\title{
Impact of the Type of Compression Materials on Manual Dexterity of Patients with Breast Cancer- Related Lymphedema (BCRL)
}

\author{
Sung-JoONG KIM, PT, PhD ${ }^{1)}$ \\ 1) Department of Physical Therapy, Kangwon National University: 3 Hwangjo-ri, Dogye-eup, \\ Samcheok-si, Gangwon-do, 245-907, South Korea.TEL: +82 540-3371,E-mail:lymphkim@ \\ kangwon.ac.kr
}

\begin{abstract}
Purpose] The aim of this study was to study manual dexterity levels provided by the type of compression garment and compression bandages of patients with breast cancer-related lymphedema (BCRL). [Methods] Twenty-six BCRL patients formed experimental group and 32 healthy volunteers who were matched to the experimental subjects were in the control group. Grip strength and manual dexterity were tested under the three conditions (the no compression condition, the garment condition, and the bandage condition) using the Nine-Hole Peg Test (NHPT), the Box and Block Test (B\&BT) and a hand-held Jamar dynamometer. [Results] The comparison showed significant differences of grip strength between the experimental group and the control group under the bandage condition. Both groups' performance abilities decreased as the thickness of the compression materials increased. The correlations between the grip strength and dexterity scores tended to be low to moderate, ranging from 0.407 (Box and Block Test) to -0.550 (Nine-Hole Peg Test) under the bandage condition. [Conclusion] The result of this study suggest that the grip strength and manual dexterity scores in patients with BCRL are influenced by the characteristics of the compression type. A wider choice of compression materials would improve on hand function in activities of daily living.

Key words: Breast cancer related-lymphedema, Nine-Hole Peg Test, Box and Block Test
\end{abstract}

(This article was submitted May 7, 2012, and was accepted May 23, 2012)

\section{INTRODUCTION}

Breast cancer-related lymphedema (BCRL) is a blockage in the one-way lymphatic transport system caused by physical trauma of the affected area due to surgery or radiation, or a complication of axillary lymph node staging for breast cancer which often results in functional impairment, and chronic disability ${ }^{1)}$. It has been reported to develop in approximately $6-30 \%$ of patients after breast cancer surgery and reduces the quality of life $\mathrm{e}^{2-4)}$.

Hand function is essential for activities of daily living for everyone, including individuals with BCRL. Individuals with hand dysfunction experience difficulties in self-care as well as fitness, recreational, and economic activities ${ }^{5)}$. Difficulty in these activities may preclude participation with peers and therefore adversely affect quality of life ${ }^{6}$.

With increasing lymphedema, the joints in the involved area become stiff and their overall range decreases ${ }^{7)}$. Joint range of motion is also negatively affected by the increase in mass. This decreased, coupled with the increased fluid tension in the subcutaneous tissue, can cause symptoms ranging from discomfort to outright pain in the lymphedematous $\mathrm{arm}^{8)}$. The decreased range and the pain can affect arm use in functional activities of self-care and work ${ }^{9}$.

Compression applications for edema control in BCRL can affect the mobility, strength, and agility that are necessary in the hand to be able to perform activities of daily living. The examination of functional activities of BCRL patients has recently received an increasing amount of attention because lymphedema has been shown to be associated with functional outcomes $^{10-12)}$. Although compression materials are used to prevent growth and decrease the size of lymphedema in everyday life ${ }^{13)}$, poor dexterity because of compression support may lead to difficulty in performance of activities of daily living, especially with functional tasks ${ }^{1,14)}$.

In our previous study, hand functions to test the arm function afforded by different types of compression bandages and compression garment in asymptomatic subjects ${ }^{15}$. However, the manual dexterity of the patients with compression support has not been studied. Therefore, the aim of this study was to objectively measure the impact of compression type on the manual dexterity of patients with BCRL.

\section{SUBJECTS AND METHODS}

A total of 26 consecutive women suffering from unilateral upper arm lymphedema due to breast cancer whose dominant hand was the right hand were recruited from Korea MLD Institute at Kangwon National University. The diagnosis of BCRL was established at least 6 months prior to the study. The women inclusion criteria were 40-49 years of age, 
moderate (volume difference $20 \%-40 \%$ ) to severe edema (difference $>40 \%$ ) and upper arm lymphedema on the dominant side. Patients who were receiving radiotherapy, who had current recurrence of breast cancer, cellulitis, venous thrombosis, or chronic inflammatory diseases, or had pre-existing neuromuscular or musculoskeletal conditions that would have affected upper extremity testing, and those who had limitation of the upper extremity joints were excluded from the study. The control group consisted of a convenience sample of 32 healthy volunteers who were matched for age, gender and the side of the dominant hand. The inclusion criteria were: $40-49$ years of age; right handed; no shoulder, elbow, hand, or cervical injuries or dysfunction in the past year; no limitation of range of motion in any joint of the dominant hand; no history of neurological impairment affecting balance, vision, or coordination; and no skin disease. The study was performed with the approval of the Health Research Ethics Board of the Korea MLD Institute at Kangwon National University. Subjects signed written informed consents forms prior to their participation.

Grip strength and manual dexterity were measured under three conditions: the no compression condition, the garment condition, and the bandage condition. A readymade compression glove with a separate long finger-type handpiece and wrist-to-shoulder sleeve (Compression sleeve, Schiebler, Germany) of $25-32 \mathrm{~mm} \mathrm{Hg}$ for the dominant hand was used for the garment condition. Garment size was matched with circumference of each subject's arm according to the manufacturer's guideline for same tightness. Bandages for the bandage condition consisted of two 4-cm elastic bandages (Mollelast, Lohmann-Rauscher, Germany), a cotton tubular stockinette (Tricofix, $6 \mathrm{~cm}$, BSN-Jobst, USA), a $10 \mathrm{~cm}$ foam padding roll (CompriFoam, BSN-Jobst, USA), and one $6-\mathrm{cm}$, one $8-\mathrm{cm}$ and two $10-\mathrm{cm}$ short stretch bandages (Comprilan, BSN-Jobst, USA).

Grip strength measures were made using a hand-held Jamar dynamometer (Sammons Preston Rolyan, Bolingbrook, USA) with standardized positioning and instruction ${ }^{16)}$ The dominant or affected upper extremity was tested 3 times, using the procedures recommended by the American Society of Hand Therapists and the sesults were expressed in kilograms. The participant was told to keep the shoulder adducted, the elbow flexed at 90 degrees, and the forearm and wrist in the neutral position without resting the arm on the table or chair, and to place her fingers on the second position of the handle of the dynamometer. The participant was asked to squeeze as hard as possible for 3 to 5 seconds and verbal encouragement was provided whenever necessary.

Manual dexterity was measured using the Nine-Hole Peg Test (NHPT) for evaluating fine motor dexterity and the Box and Block Test (B\&BT) for gross manual dexterity. NHPT was used to measure fine manual dexterity and it was performed using the product of Smith \& Nephew (London, UK). Participants were tested at a desk and chair of appropriate height with their feet placed on the floor. The procedure described by Mathiowetz et al. was followed in this study ${ }^{16)}$. The pegboard was centered in front of the subject with the container sides on the same side as the hand being tested. The instructions used were the same as those used by Mathiowetz et al. ${ }^{16)}$. The subject was required to pick up each of the nine pegs and to place them into their nine corresponding holes. The participants were instructed to pick up the pegs with the dominant or affected hand and place them one at a time into the holes as fast as possible and then to remove the pegs, one at a time, with the same hand. In this test, the time required for peg placement and removal according to the procedure was recorded. The time taken to complete the test was also recorded. High interrater reliability and moderate test-retest reliability for this test have been demonstrated, and the norms for adults up to 75 years of age and above for both genders have been established $^{16)}$. B\&BT was used to measure gross manual dexterity. This test requires the subjects to transfer, one at a time, $2.5 \mathrm{~cm}$ cubes from one (full) box across a $15.2 \mathrm{~cm}$ barrier to a second (initially empty) box. Scores were recorded as number of blocks per minute for each hand. The advantages of the B\&BT are that it has been standardized, is quick to administer (requiring $<5 \mathrm{~min}$ ), and is inexpensive. B\&BT has been shown to have good test-retest reliability, and test performance correlates highly with performance of a similar test of dexterity ${ }^{17}$.

Bandaging was performed by a trained physical therapist to ensure the same tightness of bandages with the same bandaging method, and the experimental order was randomized. This randomization ensured that each condition was perfectly balanced with respect to order. This strategy was used to minimize the combined effect of time, practice, and fatigue on the results.

Means and standard deviations were calculated for all test scores for each group. Repeated measure analyses of variance (ANOVA) and Scheffe's post hoc $t$ test were used to determine the effects of each condition on hand function. The dependent $t$ test was used to examine the differences in the mean test scores between the experimental group and the control group. The Pearson product-moment correlation coefficient was also used to determine the extent of the relationship of hand strength with dexterity scores. The collected data were analyzed using standard statistics software (SPSS ver. 17.0), and an alpha level of 0.05 was chosen for all tests.

\section{RESULTS}

Twenty-six patients with right upper arm lymphedema were enrolled in this study. Their mean age was $47.5 \pm$ 2.4 years, and their mean Body Mass Index (BMIs) was $22.7 \pm 5.4 \mathrm{~kg} / \mathrm{m}^{2}$. With regard to cancer-related treatment, nineteen patients $(73.0 \%)$ had received both surgery and radiotherapy, and the average length of time since cancer treatment was $3.2 \pm 5.4$ years. The mean volume difference compared with the unaffected contralateral limb in the experimental group was $36.5 \pm 4.7 \%$. The thirty-two healthy volunteers in the control group had a mean age of $45.8 \pm$ 2.5 years, and a mean BMI of $22.3 \pm 3.5 \mathrm{~kg} / \mathrm{m}^{2}$.

Table 1 presents the mean scores and standard deviations of grip strength. The effect of each condition by compression type on the grip strength was determined by repeated measure ANOVA. The comparison showed significant 
Table 1. Grip strength under each condition

\begin{tabular}{llllll}
\hline \multicolumn{2}{l}{ Variables } & $\begin{array}{l}\text { No compression } \\
\text { Condition (a) }\end{array}$ & $\begin{array}{l}\text { Garment } \\
\text { Condition (b) }\end{array}$ & $\begin{array}{l}\text { Bandage } \\
\text { Condition (c) }\end{array}$ & Sheffe \\
\hline EG & Dynamometer & $33.67 \pm 8.984$ & $32.78 \pm 8.11$ & $26.73 \pm 7.11$ & $\mathrm{a}<\mathrm{c}^{* *}, \mathrm{~b}<\mathrm{c}^{*}$ \\
$\mathrm{CG}$ & $(\mathrm{kg})$ & $37.02 \pm 8.40$ & $35.98 \pm 7.93$ & $31.30 \pm 8.74$ & $\mathrm{a}<\mathrm{c}^{*}$ \\
\hline
\end{tabular}

$* \mathrm{p}<0.05 ; * * \mathrm{p}<0.01$. EG, experimental group $(\mathrm{n}=26) ; \mathrm{CG}$, control group $(\mathrm{n}=32)$.

Table 2. Dexterity scores under each condition

\begin{tabular}{llllll}
\hline Variables & $\begin{array}{l}\text { No compression } \\
\text { Condition (a) }\end{array}$ & $\begin{array}{l}\text { Garment } \\
\text { Condition (b) }\end{array}$ & $\begin{array}{l}\text { Bandage } \\
\text { Condition (c) }\end{array}$ & Sheffe \\
\hline EG & Nine-Hole Peg & $17.96 \pm 2.27$ & $19.55 \pm 4.09$ & $22.69 \pm 4.23$ & $\mathrm{a}<\mathrm{c}^{* *}, \mathrm{~b}<\mathrm{c}^{* *}$ \\
CG & Test & $17.22 \pm 2.47$ & $18.73 \pm 3.76$ & $26.04 \pm 4.88$ & $\mathrm{a}<\mathrm{c}^{* *}, \mathrm{~b}<\mathrm{c}^{* *}$ \\
\hline EG & Box and Block & $81.75 \pm 8.67$ & $75.36 \pm 6.75$ & $68.96 \pm 6.90$ & $\mathrm{a}<\mathrm{c}^{* *}, \mathrm{~b}<\mathrm{c}^{* *}$ \\
CG & Test & $79.29 \pm 7.57$ & $70.68 \pm 9.22$ & $67.74 \pm 0.54$ & $\mathrm{a}<\mathrm{c}^{* *}, \mathrm{~b}<\mathrm{c}^{* *}$ \\
\hline
\end{tabular}

Mean \pm SD. EG, experimental group $(n=26)$; $C$, control group $(n=32) .{ }^{*}<<0.05 ; * * p<0.01$.

Table 3. Correlation (Pearson r) of grip strength and dexterity scores under each condition

\begin{tabular}{ccccc}
\hline \multicolumn{2}{l}{ Variables } & $\begin{array}{c}\text { No compression } \\
\text { Condition }\end{array}$ & $\begin{array}{c}\text { Garment } \\
\text { Condition }\end{array}$ & $\begin{array}{c}\text { Bandage } \\
\text { Condition }\end{array}$ \\
\hline \multirow{2}{*}{ EG } & Nine-Hole Peg Test & -0.258 & -0.306 & $-0.550^{* *}$ \\
& Box and Block Test & 0.119 & 0.277 & $0.407^{*}$ \\
\multirow{2}{*}{ CG } & Nine-Hole Peg Test & -0.088 & -0.096 & -0.146 \\
& Box and Block Test & 0.264 & 0.087 & 0.212 \\
\hline
\end{tabular}

Mean \pm SD. EG, experimental group $(n=26)$; CG, control group $(n=32) .{ }^{*} p<0.05 ; * * p<0.01$.

differences of grip strength between the experimental group and the control group under the bandage condition $(\mathrm{p}<0.05)$.

Grip strength of both groups was decreased under the bandage condition compared with the no compression and garment conditions. Post-hoc testing of the grip strength revealed significantly lower grip strength under the bandage condition than under the no compression condition $(\mathrm{p}<0.01)$ and the garment condition $(\mathrm{p}<0.05)$ in experimental group, and significantly lower grip strength under the bandage condition $(\mathrm{p}<0.05)$ than under the no compression condition in control group.

No significant difference was found in dexterity scores of the NHPT and the B\&BT between the experimental group and the control group, except for the scores of the NHPT under the bandage condition $(\mathrm{p}<0.05)$. Both two groups performances tended to worsen globally in NHPT and B\&BT. Post-hoc testing revealed the NHPT scores were higher and the B\&BT scores were lower under the bandage condition $(p<0.01)$ than under the no compression and garment conditions in both the experimental and control groups (Table 2). This means that the time needed to complete each test increased as the thickness of the compression materials increased.

Table 3 displays the Pearson correlation coefficients for the grip strength and dexterity scores of the experimental and control groups. There was a significant correlation between the grip strength and NHPT scores for fine motor dexterity and $\mathrm{B} \& \mathrm{BT}$ scores for gross motor dexterity of the experimental group under the bandage condition (Table 3 ). The correlations tended to be low to moderate, ranging from $0.407(\mathrm{~B} \& \mathrm{BT}, \mathrm{p}<0.05)$ to $-0.550(\mathrm{NHPT}, \mathrm{p}<0.01)$ for the bandage condition.

\section{DISCUSSION}

Compression therapy is one of the gold standard treatments for BCRL. It is very important that the patients wear well-fitting compression garments or compression bandaging to control edema in daily life ${ }^{18,19)}$. This study is the first to determine the fine and gross manual dexterity levels allowed by the two types of compression methods commonly used in the treatment of BCRL.

Grip strength is important for function, and it is reported that $9.07 \mathrm{~kg}$ of grip force is needed for the completion of most activities of daily living, with measures of up to $24.95 \mathrm{~kg}$ of force being normal for females ${ }^{16,20)}$. The recorded grip strength of the experimental group and the control group were greater than the normative values of their age group. However, the experimental group grip strength was weaker than that of the control group under all conditions.

Lymphedema is likely to affect hand function because of the relatively narrow confines of the anatomy of the hand ${ }^{21)}$. Specifically, all joints at their arthrokinematic level require freedom to roll and or glide to produce normal osteokinematic movement that does not strain surrounding capsule, ligaments, nerves, vascular structures, or tendons. When 
the lymphatic system is injured and lymphedema forms, the accumulation of protein-rich fluid may lead to fibrosis and thickening of the tissue. The subsequent loss of tissue extensibility, increased friction with tendon gliding, and loss of capsular space forces the hand into a position of dysfunction and decreases the range of motion ${ }^{22}$. BCRL may inhibit intrinsic muscles of the hand, and may thereby further contribute to decreased motion. Prolonged lymphedema after cancer treatment can hinder the wound healing process, prevent mobility, and cause other chronic impairments, such as adaptive shortening, adhesions, weakness, eventually to loss of function ${ }^{6,23)}$. These problems indicates that BCRL from activities may prevent joint movement resulting in atrophy from disuse.

In our investigation, evaluation of changes in manual dexterity was carried out by two objective and standardized tests of hand function, NHPT and B\&BT. The result of the fine manual dexterity test using NHPT under the bandage condition was the only one showing a significant difference between the experimental and the control group. This result suggests that the level and materials of compression have a great impact on fine manual dexterity, and that the NHPT is more sensitive at detecting manual dexterity than B\&BT. Both group's performances tended to worsen globally in NHPT and B\&BT, meaning that it was difficult to complete each test as the thickness of the compression materials increased. The results of each manual dexterity test under each condition were not surprising in that dexterity under the bandage condition was consistently poorer than under for the no compression and garment conditions in both groups. There were two reasons for this. One is that the flexibility of the bandage material may not allow as much hand function as the garment. The other is that grip strength under the bandage condition was the smallest of all the conditions. This is because the bandage material resists joint mobility. As the compression material became thicker, the level of hand function worsened. There are several factors to be considered, such as the amount of pressure, and the type of compression when compression is applied. The amount of pressure imposed by the garment and bandage varies depending on the type of material and application. Non-elastic bandage material provides more working pressure than an elastic garment and might be preferred for lymphedema, but because of its lack of flexibility, it inhibits the hand function in activities of daily living. Compression materials for patients with edema need to be developed.

There was a significant correlation between grip strength and the manual dexterity required to complete NHPT and B\&BT under the bandage condition for the experimental group. This result shows that this combination of measures adequately reflects the elements of strength and agility that are necessary in the hand to be able to perform activities of daily living.

The limitations of this study included the lack of lymphedema stage-specific data for grip strength and manual dexterity levels allowed by the two types of compression methods. The reason why we selected female subjects in their 40s is that the incidence rate of breast cancer in the 40s, which results in chronic arm lymphedema, is the highest in
South Korea ${ }^{24)}$. The results suggest that the grip strength and hand function scores of females in their 40s are influenced by the characteristics of the compression type. It further appears that strengthening exercise and development of compression materials that do not impede hand mobility, grip strength, and function would contribute to the improvement of activities of daily living and quality of life of breast cancer patients with chronic lymphedema.

The findings reported here emphasize the need to objectively measure the impact of compression type on the manual dexterity of patients with upper arm lymphedema. A wider the choice of compression materials would improve the hand function in activities of daily living. Also, strengthening exercises for the hand are needed for patients with BCRL.

\section{ACKNOWLEDGEMENT}

The study was conducted with the research grant from Kangwon National University as financial resources of the 2012 Academic Expense Grant.

\section{REFERENCES}

1) Brennan MJ, Weitz J: Lymphedema 30 years after radical mastectomy. Am J Phys Med Rehabil, 1992, 71: 12-14. [Medline] [CrossRef]

2) Hayes SC, Janda M, Cornish B, et al.: Lymphedema after breast cancer: Incidence, risk factors, and effect on upper body function. J Clin Oncol, 2008, 26: 3536-3542. [Medline] [CrossRef]

3) McLaughlin SA, Wright MJ, Morris KT, et al.: Prevalence of lymphedema in women with breast cancer 5 years after sentinel lymph node biopsy or axillary dissection: Patient perceptions and precautionary behaviors. J Clin Oncol, 2008, 26: 5220-5226. [Medline] [CrossRef]

4) Vignes S, Arrault M, Dupuy A: Factors associated with increased breast cancer-related lymphedema volume. Acta Oncol, 2007, 46: 1138-1142. [Medline] [CrossRef]

5) Boyd RN, Morris ME, Graham HK: Management of upper limb dysfunction in children with cerebral palsy: A systematic review. Eur J Neurol, 2001, 8: 150-166. [Medline] [CrossRef]

6) Saunders SR: Physical therapy management of hand fractures. Phys Ther, 1989, 69: 1065-1076. [Medline]

7) Didem K, Ufuk YS, Serdar S, et al.: The comparison of two different physiotherapy methods in treatment of lymphedema after breast surgery. Breast Cancer Res Treat, 2005, 93: 49-54. [Medline] [CrossRef]

8) Passik SD, McDonald MV: Psychosocial aspects of upper extremity lymphedema in women treated for breast carcinoma. Cancer, 1998, 83: 2817-2820. [Medline] [CrossRef]

9) Brennan MJ, DePompolo RW, Garden FH: Focused review: Postmastectomy lymphedema. Arch Phys Med Rehabil, 1996, 77: S74-S80. [Medline] [CrossRef]

10) Kim SJ, Park YD: Effects of complex decongestive physiotherapy on the oedema and the quality of life of lower unilateral lymphoedema following treatment for gynecological cancer. Eur J Cancer Care (Engl), 2008, 17: 463-468. [Medline] [CrossRef]

11) Pereira de Godoy JM, Braile DM, de Fatima Godoy M, et al.: Quality of life and peripheral lymphedema. Lymphology, 2002, 35: 72-75. [Medline]

12) Weiss JM, Spray BJ: The effect of complete decongestive therapy on the quality of life of patients with peripheral lymphedema. Lymphology, 2002, 35: 46-58. [Medline]

13) Linnitt N, Davies R: Fundamentals of compression in the management of lymphoedema. Br J Nurs, 2007, 16: 588-592. [Medline]

14) Liao SF, Huang MS, Li SH, et al.: Complex decongestive physiotherapy for patients with chronic cancer-associated lymphedema. J Formos Med Assoc, 2004, 103: 344-348. [Medline]

15) Rhee HS, Yu JH, Kim SJ: Influence of compression types on hand function: A preliminary investigation. J Phys Ther Sci, 2011, 23: 477-480. [CrossRef]

16) Oxford Grice K, Vogel KA, Le V, et al.: Adult norms for a commercially available nine hole peg test for finger dexterity. Am J Occup Ther, 2003, 57: 570-573. [Medline] [CrossRef] 
17) Desrosiers J, Bravo G, Hebert R, et al.: Validation of the box and block tes as a measure of dexterity of elderly people: Reliability, validity, and norms studies. Arch Phys Med Rehabil, 1994, 75: 751-755. [Medline]

18) Chikly B: Theory of Practice of Lymph Drainage Therapy. Arizona: I. H. H. Publishing, 2001, pp 231-284.

19) Clodius L, Foldi M: Therapy for lymphedema today. Int Angiol, 1984, 3: 207-213.

20) Goldstein DS, Robertson D, Esler M, et al.: Dysautonomias: Clinical disorders of the autonomic nervous system. Ann Intern Med, 2002, 137: 753-763. [Medline]
21) Pyke C: Massage: A helping hand for people with chronic oedema and lymphoedema. Br J Community Nurs, 2010, 15: S28-S30. [Medline]

22) Boomkamp-Koppen HG, Visser-Meily JM, Post MW, et al.: Poststroke hand swelling and oedema: Prevalence and relationship with impairment and disability. Clin Rehabil, 2005, 19: 552-559. [Medline] [CrossRef]

23) Laseter GF: Management of the stiff hand: A practical approach. Orthop Clin North Am, 1983, 14: 749-765. [Medline]

24) National Cancer center: Cancer Incidence in Korea 2008. Seoul: Ministry of Health and Welfare, 2010, pp58-60. 